that the swifts on occasion spend the night in the air, sleeping lightly as they soar at great heights above the earth. But Mr. Walpole-Bond, from many nocturnal vigils in the Horsham belfry, is convinced that swifts do return to roost after this evening flight to high altitudes. $\mathrm{He}$ has seen some of the merry-makers rush home at about 10 p.m. G.M.T., but all the birds were not home until after midnight-that is 1 a.m. by British Summer Time. These valuable observations show that the eyesight of swifts must be extremely good, as the bird must make an entry, flying at full speed, into its narrow nesting hollow during the darkest hour of the summer night.

In his chapter on the swift Mr. Walpole-Bond mentions the astonishing pertinacity of life in a click beetle. The author was handling a juvenile swift which in its agitation disgorged a click beetle. In two hours the limp, moist 'corpse' had completely revived, although it had been caught in the mouth of the parent swift and had perhaps been carried a considerable distance, and had then been given to, and swallowed by, the young swift.
Writing of the autumn migration of the swift, the author mentions a single swift seen in Sussex on October 28, 1906. This calls to the reviewer's mind that he and his wife watched for some time a pair of swifts flying backwards and forwards over the leafless birches at Aviemore on the Spey Valley in Inverness-shire, where the river bed is $700 \mathrm{ft}$. above the level of the sea, on November 11 of a recent year. That day was unusually mild, yet the Cairngorm Hills were already thickly coated with their winter snowfall, and there was severe frost a few days before, and again almost immediately after, these wandering swifts were seen. Whence they had come, and how they had survived the frost was unknown, and we sometimes wondered whether their subsequent migration south had been successful.

It has of course been proved that swifts do on occasion become torpid in their nesting hollows in spring if severe weather should catch them after their arrival at their nesting haunts, but so far as is known, there is no record of their having been found in this condition in autumn. S. G.

\title{
Chemistry of the Brain
}

Chemistry of the Brain

By Dr. Irvine H. Page. Pp. xvii +444. (London : Baillière, Tindall and Cox, 1937.) $34 s$.

INTEREST in the biochemistry and physiology 1 of the nervous system is increasingly being taken, not only by purely scientific investigators, but also by clinicians, psychiatrists and many of those who come into contact with the abnormal manifestations of the nervous system. Dr. Page's book has an appeal to all such workers, and presents a real stimulus to those for whom mental activitynormal and otherwise-is associated with the dynamic equilibria taking place in the brain.

The book commences with a brief biography of Thudicum, "the founder of brain chemistry". It passes on to a survey of our present knowledge of the sterols, the importance of which in the make-up of the brain is well known but of the significance of which in brain metabolism we are as yet ignorant. The chemistry of the phosphatides is next considored, and then Dr. Page turns to such subjects as fatty acid metabolism, cerebrosides, carbohydrates and nitrogenous metabolism. The subjects are dealt with briefly but sufficiently adequately to present the most significant findings to the elinical research worker and to those whose main interest is the study of the brain.
There are omissions, and in places the subjectmatter is out of date; but this is inevitable in a book which does not pretend to be a text-book of biochemistry and in a subject where advances are made so rapidly. Wherever possible Dr. Page keeps the clinical aspects well to the foreground, and one of the most valuable features of the book is the description of clinical findings in psychiatry and their possible interpretations in the light of our knowledge of the biochemistry of the nervous system. Effects of oxygen deprivation, of alterations in calcium ion concentration, of deprivation of magnesium and manganese, of the action of narcotics and drugs are a few of the many subjects which are considered. There is a brief survey of the parts played by the vitamins in maintaining the integrity of the nervous system, and the penultimate chapter (by Dr. J. H. Quastel) is devoted to a description of oxidations of the brain with a very brief survey of the present (that is, until 1936) situation concerning oxidations in the living cell.

References to original articles-clinical and otherwise-are copious. Much information is present which is not elsewhere readily available, and the book is a boon to biochemical and physiological workers in the psychiatric domain.

The book is well produced, but there is a fair number of misprints and incorrect formulæ. 